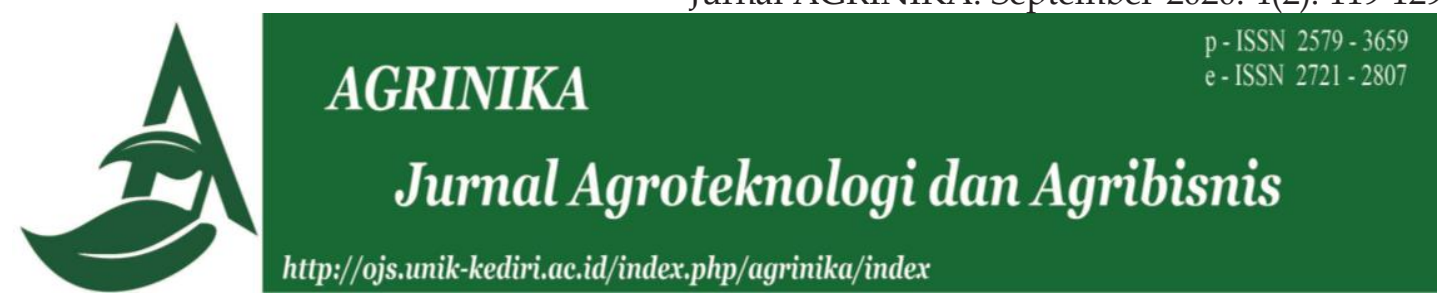

\title{
Analisis Pendapatan Usaha Pembibitan Sengon di Desa Kedunglurah Kecamatan Pogalan Kabupaten Trenggalek
}

\author{
Christa Hermylina $^{1 *}$, Yuniar Hajar Prasekti ${ }^{2}$, dan Ida Syamsu Roidah ${ }^{2}$ \\ ${ }^{1,2}$ Program Studi Agribisnis Fakultas Pertanian Universitas Tulungagung, Tulungagung, \\ Indonesia \\ *Korespondensi : christahermy98@gmail.com \\ Diterima 13 September 2020/Direvisi 15 September 2020/Disetujui 23 September 2020
}

\begin{abstract}
ABSTRAK
Usaha pembibitan sengon ini tidak terlepas dan berkaitan dengan pendapatan usaha dan juga saluran pemasaran dalam kegiatan ini. Untuk mencapai usaha yang maksimal dalam pendapatan juga diperhatikan juga dalam proses pemasaran agar lebih optimal. Tujuan penelitian ini mengetahui besaran biaya dari usaha pembibitan sengon dalam satu kali produksi, besaran pendapatan yang diterima petani, dan besaran R/C dalam usaha pembibitan sengon. Metode penelitian menggunakan wawancara langsung petani pembibitan sengon. Pengambilan sampel secara random sampling dan didapatkan sebanyak 35 responden. Penelitian ini dilakukan di Desa Kedunglurah Kecamatan Pogalan Kabupaten Trenggalek selama kurang lebih 1 bulan pada bulan Mei-Juni 2020. Metode analisis data yang digunakan biaya total, pendapatan, penerimaan, $\mathrm{R} / \mathrm{C}$ ratio. Hasil penelitian bahwa biaya usaha pembibitan tanaman sengon yaitu biaya tetap sebesar Rp552.750,00 dan biaya variabel sebesar Rp212.770.650,00 serta biaya total keseluruhan sebesar Rp217.323.400,00. Penerimaan usaha pembibitan tanaman sengon sebesar Rp1.034.000.000,00 dengan pendapatan sebesar Rp826.676.600,00 dengan rata-rata Rp23.333.617,10. Sedangkan R/C Ratio didapatkan hasil sebesar 4,76 yang dapat diartikan bahwa usaha pembibitan tanaman sengon ini menguntungkan untuk para petani pembibitan.

Kata kunci: Analisis pendapatan; Pembibitan sengon; Usahatani
\end{abstract}

\begin{abstract}
The sengon nursery business is inseparable and is related to business income and marketing channels in this activity. To achieve maximum effort in income, it is also considered in the marketing process to make it more optimal. The purpose of this study was to determine the cost of the sengon seed in one production, the amount of income received by farmers, and the amount of R/C in the sengon seed. The research method used direct interviews with sengon seed farmers. Sampling was random sampling and obtained as many as 35 respondents. This research was conducted in Kedunglurah Village, Pogalan District, Trenggalek Regency for approximately 1 month in May-June 2020. The data analysis method used is total costs, revenue, and $\mathrm{R} / \mathrm{C}$ ratio. The results that the cost of the sengon seed was a fixed cost of Rp552.750,00 and variable costs of Rp212.770.650,00 and the total cost of Rp217.323.400,00. The revenue from the sengon seed is Rp1.034.000.000,00 with an income of Rp826.676.600,00 with an average of Rp23.333.617,10. Meanwhile, the R/C Ratio yielded a result of 4.76 , which means that the sengon plant breeding business is profitable for farmers.
\end{abstract}

Keywords: Income analysis; Farming business; Sengon seed 


\section{PENDAHULUAN}

Indonesia memiliki sumber daya alam yang sangat banyak, jika sumber daya ini dikelola dengan baik akan mendatangkan kemakmuran kepada warga masyarakatnya. Salah satu jenis sumber daya alam yang dimaksud ialah tanaman perkebunan dan kehutanan. Kontribusi sektor ini dapat dibilang cukup besar untuk memenuhi kebutuhan dalam negeri maupun untuk keperluan ekspor (Irawanti et al., 2012). Sektor perkebunan dan kehutanan erat kaitannya dengan budidaya tanaman keras, yang merupakan penyedia bahan baku industry (Sari et al., 2018).

Sengon merupakan salah satu contoh tanaman keras yang umum dibudidayakan karena karakteristiknya yang cepat tumbuh, mampu tumbuh di berbagai jenis tanah, dan juga dapat dilakukan pemanenan pada umur 5 tahun (Putra et al., 2015). Sengon menjadi salah satu tanaman yang kayunya diperlukan banyak orang (Saputro \& Widayat, 2016) serta menjadi salah satu komoditi dalam segi ekonomi pada hutan rakyat yang cukup menjanjikan hasilnya (Dwi \& Ragil, 2009). Namun demikian, terdapat kendala teknis dalam usaha peningkatan mutu dan produksi sengon seperti serangan karat tumor pada batang kayu sengon (Hakim et al., 2009; Siregar et al., 2007).

Menurut Hardiatmi (2010), bagian tanaman sengon yang memberikan manfaat paling besar dari satu batang pohon sengon adalah batang kayunya. Kayu sengon ini memiliki prospek pasar yang dapat dikatakan cukup baik, karena permintaan yang sangat banyak dari konsumen dalam dan luar negeri. Kayu sengon dipergunakan antara lain untuk bahan bangunan, peralatan rumah tangga sampai pada bahan baku kertas dan kayu lapis. Kayu sengon memiliki kualitas bagus apabila dipanen umur 7 tahun (Sukarman et al., 2012).

Karakteristik kayu sengon sangat sesuai dengan kebutuhan industri, karena ringan dan warnanya putih segar. Saat ini sengon kayu olahan berupa papan dengan ukuran tertentu sebagai bahan pembuat peti, papan penyekat, pengecoran semen dalam konstruksi, industry korek api, pensil, bahan baku industry kertas pnlp, kayu lapis (plag wood), kayu pertukangan (perabotan rumah tangga), dan kerajinan seni (Kusumedi \& Jariyah, 2010). Lebih dari itu, berdasarkan hasil penelitian Ginting et al., (2013), semua komposisi media tumbuh antara serbuk gergaji kayu sengon dan bagas tebu dapat dijadikan alternatif media tumbuh jamur tiram putih. Penelitian Saputro \& Widayat, (2016) mengungkapkan bahwa limbah kayu sengon merupakan bahan baku dalam industri pengolahan briket. Dengan penggunaan yang multidimensi tersebut permintaan akan kayu sengon diperkirakan terus meningkat seiring dengan semakin meningkatnya pertumbuhan penduduk (Fuad, 2014).

Dewasa ini, usaha dalam pembibitan kayu sengon marak di tengah masyarakat pedesaan. Usaha pembibitan merupakan usaha untuk memperbanyak tanaman baik secara generatif (biji) maupun secara vegetatif (stek, cangkok, okulasi, sambung) agar memperoleh bahan tanaman yang baru menggantikan tanaman yang tua atau rusak (Indrajaya, 2013). 
Usaha pembibitan kayu sengon ini dilaksanakan secara sederhana dengan penerapan beberapa teknologi terbatas, sehingga peningkatan produktivitas dan kualitas komoditi menjadi sulit diwujudkan. Petani memproduksi bibit sengon untuk diperjual belikan, sehingga perbandingan harga dan juga biaya yang dikeluarkan menjadi perangsang untuk meningkatkan hasil. Dalam kegiatan budidaya pertanian, pembelian bibit merupakan variabel biaya terbesar (Indrajaya \& Sudomo, 2013). Hal tersebut merupakan peluang bagi petani bibit sengon.

Desa Kedunglurah merupakan salah satu desa yang menjadi tempat yang masyarakatnya melakukan usaha pembibitan tanaman sengon. Usaha yang dilakukan para petani ini cukup berkembang dan dapat membantu menunjang kebutuhan para petani maupun para pekerja yang membantu proses pembibitan itu sendiri. Analisis usaha terlebih dahulu dilakukan untuk mengetahui pendapatan yang diperoleh dalam usaha pembibitan sengon guna dapat mencapai peningkatan pendapatan.

Penelitian ini bertujuan untuk menghitung besaran biaya dari usaha pembibitan sengon dalam satu kali produksi, besaran pendapatan yang diterima petani, dan besaran $\mathrm{R} / \mathrm{C}$ dalam usaha pembibitan sengon ini.

\section{METODE PENELITIAN}

Lokasi penelitian ditentukan secara sengaja (purposive) yaitu di Desa Kedunglurah Kecamatan Pogalan Kabupaten Trenggalek. Lokasi ini dipilih karena Desa Kedunglurah adalah desa yang warga masyarakatnya adalah petani pembibitan tanaman sengon.
Sampel dalam penelitian ini adalah petani pembibitan tanaman sengon dengan jumlah sampel responden sebanyak 35 orang dengan cara random sampling atau sampel acak. Data yang dikumpulkan dalam penelitian ini adalah data primer dan data sekunder yang bersifat kuantitatif. Data primer diperoleh dari para petani pembibitan tanaman sengon dengan cara wawancara langsung. Data sekunder diperoleh dari literatur, Badan Pusat Statistik, Instansi ataupun Lembaga yang berkaitan dengan penelitian ini.

Metode analisis data yang digunakan adalah dengan metode analisis kuantitatif. Biaya total usaha pembibitan sengon adalah biaya yang dikeluarkan secara keseluruhan oleh para petani, baik biaya tetap maupun biaya tidak tetap.

Biaya tetap adalah biaya yang tidak bisa berubah sesuai dengan jumlah produksi. Sedangkan biaya tidak tetap dan biaya variabel adalah biaya yang dikeluarkan secara berubah atau berbeda setiap kali melakukan produksi dengan perubahan jumlah produk (Diniyati et al., 2013).

Penerimaan usaha adalah jumlah total pemasukan yang telah diperoleh dari hasil dari harga jual produksi dikalikan dengan jumlah barang yang dihasilkan. Persamaan yang dapat disimpulkan yaitu (Mardani et al., 2017):

$$
\mathrm{TR}=\mathrm{P} \times \mathrm{Q}
$$

Di mana :

$P=$ Harga Jual

$Q=$ Jumlah barang yang diproduksi

Pendapatan dapat diperoleh hasilnya dari total penerimaan dikurangi total biaya produksi. Dan pendapatan 
dapat dihitung menggunakan rumus (Zahara et al., 2016):

$$
\mathrm{P}=\mathrm{TR}-\mathrm{TC}
$$

Di mana :

$\mathrm{P}=$ Pendapatan bersih usahatani $(\mathrm{Rp})$

$\mathrm{TR}=$ Total penerimaan usahatani $(\mathrm{Rp})$

$\mathrm{TC}=$ Total Biaya $(\mathrm{Rp})$

Cara menghitung $\mathrm{R} / \mathrm{C}$ ratio yaitu dengan membagi jumlah penerimaan dengan total biaya (tetap +variabel). Dengan rumus persamaan sebagai berikut (Adminami01, 2020):

$$
\frac{\mathrm{R}}{\mathrm{C}} \text { Ratio }=\frac{\mathrm{TR}}{\mathrm{TC}}
$$

Di mana:

$\mathrm{TR}=$ Total Penerimaan (Rp)

$\mathrm{TC}=$ Total Biaya $(\mathrm{Rp})$

Jika:

$\mathrm{R} / \mathrm{C}>1$ maka usaha yang dilakukan dapat dinyatakan untung,

$\mathrm{R} / \mathrm{C}<1$ maka usaha yang dilakukan dapat dinyatakan merugi.

\section{HASIL DAN PEMBAHASAN}

Biaya Usaha Pembibitan Tanaman Sengon

Biaya dalam usaha pembibitan tanaman sengon adalah biaya yang dikeluarkan petani guna menunjang kegiatan pembibitan yang dilakukan yang meliputi biaya tetap dan biaya tidak tetap. Menurut penelitian Indrajaya \& Sudomo, (2013), biaya yang dibutuhkan dalam usahatani tanaman sengon terdiri dari penyediaan bahan tanaman, pupuk, dan peralatan. Berdasarkan hasil pantauan di lapangan, petani sengon mengeluarkan biaya tetap yang merupakan biaya penyusutan peralatan dan biaya tidak tetap atau biaya variabel yang terdiri dari biaya benih, polybag, tanah, pupuk, obatobatan, plastik sungkup, bambu, dan biaya tenaga kerja. Lebih rinci mengenai biaya-biaya yang dikeluarkan petani sengon di Desa Kedunglurah dapat dilihat pada Tabel 1 di bawah ini.

Tabel 1. Biaya total dan rata-rata usaha pembibitan tanaman sengon di Desa Kedunglurah

\begin{tabular}{lrr}
\hline \multicolumn{1}{c}{ Uraian } & Jumlah (Rp) & \multicolumn{1}{c}{ Rata-Rata } \\
\hline Biaya Tetap (FC) & & \\
1. Biaya Penyusutan Alat & 4.552 .750 & $130.078,00$ \\
Biaya Tidak Tetap (VC) & & \\
1. Benih & 16.217 .250 & $463.350,00$ \\
2. Polybag & 26.392 .500 & $754.071,43$ \\
3. Tanah & 51.699 .900 & $1.477 .140,00$ \\
4. Pupuk & 64.564 .000 & $1.844 .685,70$ \\
5. Obat-obatan & 22.193 .600 & $634.102,86$ \\
6. Plastik Sungkup & 10.342 .400 & $295.497,14$ \\
7. Bambu & 3.661 .000 & $104.600,00$ \\
8. Tenaga Kerja & 17.700 .000 & $505.714,29$ \\
\hline Total Jumlah Biaya & 217.323 .400 & $6.209 .240,00$ \\
\hline
\end{tabular}

Sumber: Data primer diolah tahun 2020

Berdasarkan tabel di atas dapat diketahui bahwa biaya yang dikeluarkan oleh para petani dalam usaha pembibitan tanaman sebesar
Rp217.323.400,00 dengan rata-rata sebesar Rp6.209.240,00. Biaya tetap sebesar Rp4.552.750,00 dengan rata-rata 
Rp130.078,57 dan biaya tidak tetap sebesar Rp 212.770.650,00.

Hasil penelitian Payung et al., (2012) menunjukkan bahwa terdapat perbedaan nilai perkecambahan benih tanpa perlakuan (kontrol) dengan benih yang diberikan perlakuan. $\mathrm{Hal}$ ini membuktikan bahwa benih sengon yang diberi perlakuan bermanfaat mempercepat terjadinya proses perkecambahan. Petani di lokasi penelitian, sayangnya, tidak terlalu melakukan perlakuan pendahuluan bagi benih yang diusahakan, padahal tujuan dari perlakuan benih adalah untuk menambah kecepatan dan keseragaman berkecambah benih.

Petani sengon di Desa Kedunglurah pada umumnya hanya menggunakan tanah biasa dalam pembibitan tanaman sengon. Padahal berdasarkan penelitian dari Sukarman et al., (2012), terdapat perbedaan pertumbuhan tinggi dan diameter bibit sengon pada berbagai media tumbuh yang diuji. Kecenderungan pertumbuhan tinggi dan diameter bibit sengon yang terbaik adalah yang ditanam pada media tumbuh tanah lapisan atas dan pada media tumbuh campuran tanah lapisan atas dengan sekam bakar. Begitu pula halnya, kombinasi media tumbuh yang memberikan pertumbuhan jumlah daun bibit sengon terbaik adalah pada media tumbuh tanah lapisan atas dan sekam bakar. Selanjutnya, Indrajaya (2013) mengungkapkan bahwa kualitas tempat tumbuh memberikan pengaruh yang besar terhadap tingkat pertumbuhan sengon. Namun demikian, informasi ini belum tentu digunakan oleh petani.

Obat-obatan yang digunakan oleh petani diperuntukkan bagi penyakit yang kerap kali menyerang bibit sengon. Hal ini wajar terjadi karena bibit sengon ditanam secara monokultur sehingga tanaman ini mempunyai masalah klasik, yaitu mudah terserang hama dan penyakit seperti hama penggerek batang Xystrocera festiva, damping off, dan karat puru.

Untuk mengatasi hal ini sebetulnya petani tidak hanya bergantung kepada penggunaan obat-obatan. Juniarti et al. (2013) menyatakan bahwa yang diperlukan utamanya adalah bibit sengon unggul yang dihasilkan dari program pemuliaan. Untuk melaksanakan program pemuliaan, maka diperlukan keragaman genetik yang tinggi. Pengetahuan tentang keragaman genetik sangat penting sebagai dasar pengembangan tanaman sengon melalui program pemuliaan. Oleh karena itu dalam upaya pemuliaan pohon, dalam membangun kebun benih untuk memperbaiki dan menghasilkan pohon yang baik dan resisten terhadap hama dan penyakit harus dilakukan sistem penanaman dengan melihat hubungan kekerabatan. Apabila anakan berasal dari populasi yang berdekatan maka penanamannya dilakukan sangat berjauhan.

Penerimaan dan Pendapatan Usaha Pembibitan Tanaman Sengon

Penerimaan usaha diperoleh dari hasil perkalian antara produksi dengan harga jual produk pada saat itu (Indrajaya \& Sudomo, 2013). Besarnya penerimaan yang didapatkan petani dipengaruhi oleh jumlah produksi yang telah dihasilkan dan besaran harga yang diberikan. Sedangkan pendapatan diperoleh dari hasil pengurangan antara penerimaan dengan biaya total dalam usaha pembibitan ini (Ginting et al., 2013). 
Pendapatan ini menjadi salah satu titik nilai yang menjadi penentu tingkat keberhasilan petani dalam melakukan usaha pembibitan ini.

Menurut Zahara et al. (2016), produksi yang tinggi perlu didukung dengan kebijakan harga, agar petani termotivasi untuk melakukan usahatani. Selain itu, ketersediaan sarana produksi juga penting, seperti ketersediaan pupuk. Pada saat mau melakukan pemupukan, petani sulit mencari pupuk karena adanya kelangkaan pupuk. Biaya-biaya, pendapatan dan keuntungan usahatani tergantung dari harga-harga sarana produksi dan harga jual produk. Usahatani merupakan cara-cara petani menentukan, mengorganisasikan dan melakukan pengkoordinasian penggunaan faktorfaktor produksi seefektif dan seefisien mungkin sehingga usaha tersebut memberikan pendapatan semaksimal mungkin. Faktor tersebut dibagi menjadi dua, yaitu (1) faktor internal yang terdiri dari umur petani, pendidikan, pengetahuan, pengalaman dan keterampilan, jumlah tenaga kerja keluarga, luas lahan dan modal ; dan (2) faktor eksternal yang terdiri dari input (ketersediaan dan harga), output (permintaan dan harga).

Sementara itu, Hakim et al. (2009) menyatakan bahwa persoalan harga sengon merupakan bagian dari masalah tataniaga kayu sengon yang tidak dapat dipisahkan karena mempunyai dampak langsung terhadap pelaku dalam pemasaran kayu sengon. Pada sisi sistem pemasaran kayu sengon, pendapatan petani akan meningkat dengan semakin efisiennya saluran pemasaran kayu tersebut seiring dengan peningkatan harga di tingkat industri. Sementara itu persoalan kelancaran pemasaran sangat tergantung pada kualitas produk yang dihasilkan oleh petani produsen dan juga upaya penyempurnaan kinerja lembagalembaga pemasaran dan sistem pemasarannya sendiri.

Adapun rata-rata jumlah penerimaan dan juga pendapatan usaha pembibitan tanaman sengon di Desa Kedunglurah adalah sebagai berikut:

Tabel 2. Penerimaan dan pendapatan usaha pembibitan tanaman sengon di Desa Kedunglurah

\begin{tabular}{llrr}
\hline No & \multicolumn{1}{c}{ Uraian } & Jumlah & \multicolumn{1}{c}{ Rata-Rata } \\
\hline 1 & Produksi (batang) & - & $29.543,00$ \\
2 & Penerimaan (Rp) & 1.034 .000 & $29.542 .857,00$ \\
3 & Biaya Total (Rp) & 217.323 .400 & $6.209 .240,00$ \\
4 & Pendapatan (Rp) & 816.676 .600 & $23.333 .617,10$ \\
\hline
\end{tabular}

Sumber: Data primer diolah tahun 2020

Berdasarkan Tabel 2 di atas, dapat diketahui bahwa jumlah hasil produksi pembibitan tanaman sengon yang dihasilkan oleh para petani sebanyak 29.543 batang dengan rata-rata penerimaan sebesar Rp29.542.857,10.
Sedangkan pendapatan yang diperoleh oleh para petani pembibitan sebesar Rp816.676.600,00 dengan rata-rata sebesar Rp23.333.617,10. Sehingga usaha pembibitan tanaman sengon ini dikatakan dapat menguntungkan karena 
dari hasil penerimaan dan juga pendapatan dapat menutup seluruh biaya yang dikeluarkan dalam sekali masa pembibitan sengon.

Berdasarkan pengamatan di lapangan, meski sebagian besar petani responden hanya menjadi petani pembibitan, sebagian kecil petani merupakan petani yang juga melakukan petani tanaman sengon yang menjual produk kayu sengon. Analisis singkat penerimaan petani yang menjual produk kayu sengon adalah bahwa sengon dapat memberikan nilai ekonomi yang cukup besar apabila harga sengon dengan diameter rata-rata $15 \mathrm{~cm}$ adalah Rp150.000,00 maka dalam enam tahun petani akan mendapatkan Rp41.250.000,00 per hektar atau setiap bulan petani hutan rakyat akan menerima penghasilan tambahan sebesar Rp600.000,00 Selain itu, menurut Dwi \& Ragil (2009), selama enam tahun petani dan masyarakat sekitar lokasi lahan atau kebun sengon juga akan memperoleh keuntungan tambahan (intangible benefit) yaitu lingkungan yang sehat.

Hal ini sejalan dengan penelitian dari Hardiatmi (2010) yang mengemukakan pengalaman petani penanam sengon, di mana pendapatan yang diperoleh dari penjualan hasil-hasil yang dipungut setelah dikurangi biaya yang diperlukan menghasilkan keuntungan yang cukup besar. Penelitian tersebut mengungkapkan bahwa pada tahun 2003, harga kayu sengon di pasaran mencapai Rp250.000,00 per $\mathrm{m}^{3}$, sehingga saat ini harga kayu sengon meningkat menjadi Rp650.000,00 per $\mathrm{m}^{3}$ atau lebih. Jika dihitung nilai kelayakannya, berinvestasi tanaman sengon cukup menguntungkan. Sebagai gambaran, produksi kayu sengon umur 5 tahun pada tanah yang baik adalah 240 $\mathrm{m}^{3}$ per hektar. Jika dijual setara dengan Rp140 juta. Bahkan sejumlah analisis menyebutkan bahwa harga kayu sengon diprediksi akan terus meningkat secara rasional sekitar 4 hingga 5 tahun ke depan menjadi Rp1 Juta per $\mathrm{m}^{3}$. Hal ini berdasarkan pada permintaan pasar internasional dan domestik terhadap sengon yang terus meningkat karena sengon dikenal sebagai kayu budidaya yang dapat mengurangi tekanan terhadap hutan alam. Keuntungan lain dari penggunaan kayu sengon sebagai bahan baku panel kayu adalah selain harganya relatif murah. Hal ini memicu bisnis industri kayu yang menggunakan bahan baku sengon yang pada akhirnya semakin banyak petani menanam sengon, menyebabkan hutan rakyat berkembang.

\section{Analisis Rasio Penerimaan (R/C Ratio)}

Nilai $\mathrm{R} / \mathrm{C}$ ratio diperoleh dari pembagian antara penerimaan dengan biaya total produksi. Tabel 3 berikut ini menampilkan nilai $\mathrm{R} / \mathrm{C}$ pada usaha pembibitan tanaman sengon yang dapat dikatakan usaha yang menguntungkan bagi para petani.

Menurut Diniyati et al. (2013), seringkali petani kurang memperdulikan aspek finansial dari usahatani tanaman perkebunan/kehutanan. Usaha dalam bidang ini belum menjadi agribisnis yang menghasilkan keuntungan layak 
Tabel 3. Nilai R/C ratio usaha pembibitan tanaman sengon

\begin{tabular}{rlr}
\hline No & Uraian & Jumlah \\
\hline 1 & Penerimaan (Rp) & $1.034 .000 .000,00$ \\
2 & Biaya Total & $217.323 .400,00$ \\
3 & R/C ratio & 4,76 \\
\hline
\end{tabular}

Sumber: Data primer diolah tahun 2020

secara ekonomi dan menjadi bentuk investasi yang handal. Tidak dipungkiri bahwa usaha ini masih menjadi usaha sampingan bagi masyarakat. Hal ini mengakibatkan kontribusi pembangunan di bidang ini belum dapat teranalisis dengan baik untuk menjadi masukan dalam perencanaan perekonomian suatu daerah.

Tantangan dan Prospek Usahatani Sengon di Desa Kedunglurah

Ada tiga hambatan yang dihadapi petani sengon di lokasi penelitian, yaitu hambatan silvikultur, pengorganisasian petani, dan pemasaran. Dari silvikultur, pertumbuhan tanaman sengon seringkali tidak seragam walaupun ditanam pada lahan dengan waktu dan perlakukan yang sama. Hal ini diduga karena kondisi tanah yang tidak sama dan kualitas bibit yang tidak seragam. Permasalahan yang sangat mengganggu budidaya sengon di lokasi penelitian adalah penyakit karat tumor atau karat puru karena dapat mematikan sengon di tingkat semai sampai tegakan.

Di samping itu, selama ini petani di lokasi penelitian menjual kayu per pohon atau bahkan per hamparan lahan dengan sistem tebas, langsung menerima uang tunai tanpa menebang, mengukur, dan menghitung volume sendiri. Teknik penjualan demikian dipandang belum dapat memaksimalkan nilai uang hasil jual kayu yang diterima oleh petani. Supaya petani tidak dirugikan dalam perhitungan harga kayu, sebaiknya grader dari pabrik pengolahan kayu atau depo kayu melakukan grading kayu di lahan petani setelah batang pohon sengon dipotongpotong menjadi sortimen. Dengan demikian petani diharapkan dapat menjual kayu dalam bentuk sortimen, dalam satuan meter kubik, bukan per batang pohon atau per hamparan lahan dengan sistem tebas (Irawanti et al., 2012)

Prospek pengembangan agribisnis sengon rakyat sangat prospektif atau baik untuk dikembangkan (Putra et al., 2015). Hal ini dilihat dari kondisi hulu hingga hilir yang dimulai dari perencanaan dan pengelolaan sarana produksi yang sudah terencana, penerapan cara budidaya sengon yang sudah cukup baik, dan sektor pengolahan hasil kayu sengon banyak diminati sehingga aspek pasar dan pemasaran kayu sengon sudah jelas.

Prospek pengembangan usaha kayu rakyat seyogyanya menjadi peluang bagi petani sengon untuk meningkatkan nilai tambah dari usahatani sengon yang mereka lakukan. Untuk lebih meningkatkan nilai tambah bagi petani, beberapa pilihan strategi yang dapat dipertimbangkan, yaitu membangun informasi untuk menciptakan akses pasar, peningkatan kapasitas dan kemampuan petani, peningkatan kapasitas dan kemampuan kelompok tani agar dapat 
berperan sebagai penjual log ke industri dan membangun kemitraan antara industri dan petani (Parlinah et al., 2015). Sarana dan prasarana dan jasa penunjang yang sudah baik, merupakan pendukung usaha tersebut seperti lembaga keuangan, transportasi dan jalan yang lancar, lembaga kelompok tani serta ketersediaan sumber air dan listrik yang merata.

Sari et al. (2018) berpendapat bahwa nilai NPV pada hutan rakyat lebih tinggi dibandingkan dengan tanaman semusim sehingga hutan rakyat lebih menguntungkan secara ekonomi dibandingkan tanaman semusim. Secara ekologi hutan rakyat mampu memperbaiki kondisi lahan dan kesuburan tanah secara perlahan melalui masukan seresahnya, serta dapat menekan limpasan permukaan karena tutupan kanopinya dan meningkatkan cadangan karbon. Namun demikian, masalah penyedian modal masih menjadi masalah utama dalam usaha tani ini.

\section{KESIMPULAN}

Biaya usaha pembibitan tanaman sengon termasuk biaya tetap maupun biaya tidak tetap. Biaya tetap sebesar Rp4.552.750,00 dan biaya tidak tetap sebesar Rp212.770.650,00 serta biaya total keseluruhan sebesar Rp217.323.400,00.

Penerimaan usaha pembibitan
tanaman sengon sebesar Rp1.034.000.000,00 dengan pendapatan sebesar Rp826.676.600,00 dengan rata-

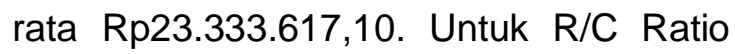
didapatkan hasil sebesar 4.76 yang dapat diartikan bahwa usaha pembibitan tanaman sengon ini menguntungkan untuk para petani pembibitan.
Para petani hendaknya melakukan hal-hal yang dapat meningkatkan usaha pembibitan sengon ini agar terus memberikan keuntungan yang baik bagi para petani.

\section{DAFTAR PUSTAKA}

Adminami01. (2020). Mengetahui Pengertian dan Rumus B/C Ratio dan R/C Ratio. Rumusrumus.Com. https://rumusrumus.com/rumus-b-cratio-dan-r-c-ratio/

Diniyati, D., Achmad, B., \& Santoso, B. (2013). ANALISIS FINANSIAL AGROFORESTRY SENGON DI KABUPATEN CIAMIS (Studi Kasus di Desa Ciomas Kecamatan Panjalu). Jurnal Penelitian Agroforestry, 1(1), 13-30.

Dwi, H. R., \& Ragil, B. W. M. P. (2009). KAJIAN SENGON ( Paraserianthes falcataria ) SEBAGAI POHON BERNILAI EKONOMI DAN LINGKUNGAN. Jurnal Penelitian Hutan Tanaman, 6(3), 201-208.

Fuad, I. L. (2014). Analisis Efisiensi Usaha dan Pemasaran Bibit Sengon Di desa kedunglurah kecamatan pogalan kabupaten trenggalek. Universitas Muhammadiyah Malang.

Ginting, A. R., Herlina, N., \& Tyasmoro, S. Y. (2013). STUDI PERTUMBUHAN DAN PRODUKSI JAMUR TIRAM PUTIH ( Pleorotus ostreatus) PADA MEDIA TUMBUH GERGAJI KAYU SENGON DAN BAGAS TEBU. Jurnal Produksi Tanaman, 1(2), 1724.

Hakim, I., Indartik, I., \& Yosefi Suryandari, E. (2009). Analisis Tataniaga Dan Pasar Kayu Sengon Di Kabupaten Wonosobo Dan Kabupaten 
Temanggung, Jawa Tengah. Jurnal Penelitian Sosial Dan Ekonomi Kehutanan, 6(2), 99-115. https://doi.org/10.20886/jpsek.2009.6 .2.99-115

Hardiatmi, S. (2010). INVESTASI TANAMAN KAYU SENGON DALAM WANATANI CUKUP MENJANJIKAN JM. Innofarm: Jurnal Inovasi Pertanian, 9(2), 17-21.

Indrajaya, Y. (2013). PENENTUAN DAUR OPTIMAL HUTAN TANAMAN SENGON ( Paraserianthes falcataria ( L .) Nielsen ) DENGAN METODE FAUSTMANN. Jurnal Penelitian Agroforestry, 1(1), 31-40.

Indrajaya, Y., \& Sudomo, A. (2013). Analisis Finansial Agroforestry Sengon dan Kapulaga di Desa Payungagung Kecamatan Panumbangan Ciamis. Jurnal Penelitian Agroforestry, 1(2), 123132.

Irawanti, S., Suka, A. P., \& Ekawati, S. (2012). MANFAAT EKNOMI DAN PELUANG PENGEMBANGAN HUTAN RAKYAT SENGON DI KABUPATEN PATI. Jurnal Penelitian Sosial Dan Ekonomi Kehutanan, 9(3), 126-139.

Juniarti, U., Dwita, R., Silvikultur, D., \& Kehutanan, F. (2013). Keragaman Genetik Populasi Sengon

Paraserianthes falcataria ( $L \quad$ ) Nielsen ) pada Hutan Rakyat di Jawa Berdasarkan Penanda RAPD Genetic Diversity of Sengon Population ( Paraserianthes falcataria ( L )) in Java Community. Jurnal Silvikultur Tropika, 3(2).

Kusumedi, P., \& Jariyah, N. A. (2010). Analisis Finansial Pengelolaan Agroforestri dengan Pola Sengon
Kapulaga di Desa Tirip Kecamatan Wasalintang Kabupaten Wonosobo. Jurnal Penelitian Sosial Dan Ekonomi Kehutanan, 7(2), 93-100.

Mardani, Nur, T. M., \& Satriawan, H. (2017). Analisis Usaha Tani Tanaman Pangan Jagung di Kecamatan Juli Kabupaten Bireuen. S. Pertanian, 1(3), 203-204.

Parlinah, N., Irawanti, S., Suka, A. P., \& Ginoga, K. L. (2015). Distribusi Nilai Tambah dalam Rantai Nilai Kayu Sengon (Paraserianthes falcataria) dari Kabupaten Pati, Jawa Tengah, Indonesia. Jurnal Penelitian Sosial Dan Ekonomi Kehutanan, 12(2), 7787.

Payung, D., Prihatiningtyas, E., \& Nisa, S. N. (2012). UJI DAYA KECAMBAH BENIH SENGON (Paraserianthes falcataria (L.) Nielsen) DI GREEN HOUSE. Jurnal Hutan Tropis, 13(2), 132-138.

Putra, D. S. A., Lestari, D. A. H., \& Affandi, M. I. (2015). KELAYAKAN FINANSIAL DAN PROSPEK PENGEMBANGAN AGRIBISNIS SENGON (Albazia falcataria) RAKYAT DI KECAMATAN KEMILING KOTA BANDAR LAMPUNG. JIIA, 3(4), 345-353.

Saputro, D. D., \& Widayat, W. (2016). Karakterisasi limbah pengolahan kayu sengon sebagai bahan bakar altrnatif. Sainteknol, 14(1), 21-29.

Sari, R. R., Hairiah, K., \& Suyanto. (2018). Karakteristik Hutan Rakyat Jati dan Sengon serta Manfaat Ekonominya di Kabupaten Malang. JEPA, 2(2), 129-137.

Siregar, U. J., Rachmi., A., Massijaya, M. J., Ishibashi, N., \& Ando, K. (2007). 
Christa Hermylina, Analisis Pendapatan Usaha...

Economic analysis of sengon (Paraserianthes falcataria) community forest plantation, a fast growing species in East Java, Indonesia. Forest Policy and Economics, 9(7), 822-829.

Sukarman, Kainde, R., Rombang, J., \& Thomas, A. (2012). PERTUMBUHAN BIBIT SENGON ( Paraserianthes falcataria ) PADA BERBAGAI MEDIA TUMBUH. Eugenia, 18(3), 215-221.

Zahara, Mawardi, R., \& Irawati, A. (2016). ANALISIS BIAYA, PENDAPATAN DAN FAKTOR-FAKTOR YANG BERHUBUNGAN DENGAN PENDAPATAN USAHATANI PADI DI KABUPATEN PRINGSEWU. Prosiding Seminar Nasional Agroinovasi Spesifik Lokasi Untuk Ketahanan Pangan Pada Era Masyarakat Ekonomi ASEAN, 1, 553-560. 